\title{
Comparison of three surgical approaches for fractures of the mandibular condyle
}

\author{
Abhinandan Patel K N $\mathbf{N}^{1}$, Girish. $\mathbf{G}^{2 *}$, Sneha T $\mathbf{R}^{3}$ \\ ${ }^{\mathbf{1}}$ Associate Professor and HOD, ${ }^{2}$ Assistant Professor, ${ }^{3}$ Senior Resident, Sanjay Gandhi Institute of Trauma and Orthopedics, Bengaluru, \\ Karnataka, India \\ *Corresponding Author: Girish. G \\ Email: drgirishgowda@gmail.com
}

\begin{abstract}
Mandibular condylar process is the third most commonly fractured bone. Various surgical approaches to fix this condyle are described hitherto testify to the advantages and disadvantages of various surgical techniques used for approaching the condyle in such fracture cases. Here we have compared three such surgical techniques.

Aim: The aim of this study was to compare the outcome of various surgical approaches for the treatment of condylar fractures.

Materials and Methods: A retrospective study of 60 patients who were diagnosed with condylar fracture and required open reduction and internal fixation were considered. 59 cases were unilateral and 1 was bilateral. 60 patients were categorized into three groups of 20 each according to the surgical approach performed. All data were evaluated using the patient's records including the radiological imaging. Parameters like post-op IMF, facial nerve injury, scar, wound infection, malocclusion and plate retrieval were noted.

Results: The submandibular approach showed the worst outcome in terms of facial nerve injury, unfavorable scar, and wound infection. No significant differences between the pre-auricular and trans parotid approaches were detected in the above mentioned parameters. Post op infection was high in the pre auricular group. $10 \%$ of the cases in the pre auricular group had to undergo plate retrieval.

Conclusion: Inferior neck condylar fractures benefit from submandibular approach, high neck fractures from trans parotid approach and condylar head fractures via preauricular approach.
\end{abstract}

Keywords: Condylar fractures, Open reduction, Various surgical approaches.

\section{Introduction}

The second most commonly fractured bone is the mandible in the maxillofacial skeleton, due to its position and prominence accounting for $40-60 \%$ of all facial fractures, out of which $29.3 \%$ of them are condylar fractures. ${ }^{1}$ Diagnosis and management of condylar fractures are one of the most controversial topic discussed. ${ }^{2}$ Literature review reveals the several shortcomings in most studies which include randomization, classification of condylar fracture types and the comparison of different surgical approaches. There are also a very low number of patients reported. Hence it is not possible to perform a reliable metaanalysis. $^{3}$ There are numerous classification for the categorization of condylar fractures. These wide systems of classifications used internationally are making it difficult to compare the treatment outcomes of these fractures. Studies by Ellis and Throckmorton published in 2000 conclude that patients who had ORIF had better restitution of condyle position and reinforcement of their fractured condylar processes. Patients who underwent closed reduction had displacement of the condylar processin the coronal plane, which persisted for up to 1 year, and had a significant shortening of the mandibular ramus on the fractured side though bite forces did not show any significant difference. Classification differentiates condylar head fractures into intra- and extracapsular, ${ }^{4}$ or based on the level of fracture into head neck and subcondylar fractures. ${ }^{5}$ Six types of condylar fractures were identified by Spiessl and Schroll which included displacement and dislocation of the fracture fragments. More precise definition of the terms condylar neck and condylar base was presented by Loukuta et al. Two main treatment modalities are advised for the treatment of condylar fractures, one being closed reduction and the other open reduction with internal fixation. Open reduction can be performed by various approaches. To assess the most appropriate surgical approach for condylar fractures aesthetic and the functional outcomes should be considered. Hence in our study we have compared the submandibular, preauricular and the transparotid approaches to the condyle with respect to these parameters and correlated them with the specific features of condylar fractures.

\section{Materials and Methods}

A retrospective study was conducted of the inpatient and outpatient medical records of patients with mandibular condylar fractures at the department of facio-maxillary surgery, Sanjay Gandhi institute of trauma and orthopedics. The inclusion criteria were: patients with condylar fracture that required open reduction and internal fixation, age between 18-60 years irrespective of gender. The exclusion criteria was- patients with pre-existing medical conditions, infected fracture site, patients who were treated by closed reduction. A total of 60 cases were included in the study. All patients were classified based on Spiessl and Schroll classification of condylar fractures, using radiological examination, into three groups- preauricular group (type VI), submandibular group (type II and type IV), and the transparotid group (type IIIb, type IIIc, and type V). In all the cases miniplates were used for internal fixation. Preauricular approach was preformed according to Eckelt. For submandibular approach the incision was given two fingers below the mandibleand for the transparotid approach incision was given $2.5-3.5 \mathrm{~cm}$ vertically below the lobule of the ear. All patients' records were followed up for 6 months. All data were evaluated using the patient's records including the radiological imaging. Parameters like post-op IMF, 
palsy of facial nerve, scar, wound infection, malocclusion and plate retrieval were noted. The data were evaluated using SPSS 19.0. significant differences between the various approaches were identified using chi-square test. A p-value less than 0.05 was regarded as statistically significant.

\section{Results}

60 condylar fractures were included in this study. $16.6 \%$ of them were women whereas $83.4 \%$ were men with a $\mathrm{p}$ value of 0.43 . The mean age in the preauricular group was 35.10 years, 32.95 years in the submandibular group and 34.05 years in the transparotid group with a standard deviation of $10.026,8.906$, and 8.432 respectively. RTA was the major etiology of injury in all the three groups followed by selffall and assault. P-value was found to be significant (p0.03 ). $5 \%$ of case in the submandibular group was bilateral, which was managed by closed reduction on one side. 55\% of the cases in pre-auricular and trans-parotid and 50\% of cases in the submandibular group were on the right side. (pvalue -0.98 ). $85 \%$ of fractures in the pre-auricular group, $75 \%$ of fractures in the sub-mandibular group and $45 \%$ of the fractures in the trans-parotid group were associated with other fractures of the facial skeleton. A p-value of 0.022 was obtained which was found to be significant. Post-op IMF was present in $10 \%$ of preauricular group when compared $0 \%$ in the other two groups with a p-value of 0.12 facial nerve palsy was seen in 5\% of preauricular cases, $20 \%$ of submandibular group and $15 \%$ of trans-parotid group with a p-value of 0.36. unfavorable scar formation was recorded in $10 \%$ of pre-auricular group, $30 \%$ of submandibular group and trans-parotid group (p-value- 0.22). Wound infection was seen in $10 \%$ of preauricular group, $20 \%$ of submandibular group and 5\% of transparotid group with a $\mathrm{p}$-value of 0.12 . Malocclusion was seen in $10 \%$ of preauricular cases, and none in the other two groups. (pvalue- 0.12 ). $10 \%$ of cases in the preauricular group and $5 \%$ of cases in the transparotid group had to undergo plate retrieval with a p-value of 0.12 .

\section{Discussion}

About one third of all mandibular fractures are of the mandibular condylar. ${ }^{8}$ Treatment plan of these fractures are controversial, either to treat surgically (open reduction and internal fixation) or functionally (closed reduction). ${ }^{9}$ In adult patients surgical treatment depends on the type and displacement of the fracture. ${ }^{10}$ Based on the height and position of the fractured segment, various approaches to the condylar process are described. The only criterion for selection of the approach is done with the distance between the incision and level of fracture. ${ }^{11}$ The choice of surgical approach to the condyle depends upon the individual maxillofacial surgeon and is based on their experience with technique and their personal beliefs. In this study Spiessl and schroll ${ }^{12}$ classification of condylar fractures was used. Practically, all the fractures were divided into 3 groups, based on the type of fracture and the most suitable approach for it. Spiessl and schroll type I condylar fractures were not included in the study as they could be managed with closed reduction. The mean age for condylar fractures to occur was between 30-35 years in all the 3 groups when compared to a study by Newman et al where it ranged between 17-32 years. ${ }^{13}$ In this study males constituted $83.4 \%$ of the total cases, indicating the fact that men constitute the main working force in our society. This supports the statistics of Wong and Badar and Syed where there was male predominance. ${ }^{14,15}$ On the other hand, Zachariades et al., in a review study of 466 condylar fractures cases found no significant difference between males and females. ${ }^{8}$ This can be attributed to the fact that more women work outdoors in some occupations which leads to more exposure to craniomaxillofacial fractures. RTA was the most common cause of condylar fracture with $(78.3 \%)$. This data were similar to a study done by Sawazakiet al. ${ }^{16}$ who mentioned that RTA was the most common cause of condylar fracture $(55.33 \%)$. In our study, falls, assault and violence were of less frequency. The isolated condylar fracture was presented in about $31.66 \%$ of cases. The rest of cases were associated with other mandibular fractures. Anterior mandibular fractures were present in half of cases of associated fractures. The frequency of angle (16.6\%) and ZMC (5\%) came behind Zachariadeset al. ${ }^{8}$ had mentioned that condylar fractures resulted from the transmission of force which is not fully absorbed in the area of its primary application.5\% of the total cases were bilateral cases. The presence of bilateral condylar fractures in isolation did not mandate an ORIF. This was in accordance with management of Kellman ${ }^{17}$. In contrast, Ellis believed that any unilateral condylar fracture could be treated with MMF only ${ }^{18}$. In addition, he did not believe that he could manage bilateral condylar fractures efficiently by MMF. The complication rates found in this study are within reported ranges. The incidence of facial nerve injury has ranged from $0-21 \%$. It was seen more in the submandibular approach $(20 \%)$. This could be attributed to the subcutaneous dissection which traverses the marginal mandibular nerve deeply, in the submandibular approach when compared to the superficial traversing in the transparotid group. ${ }^{7}$ The least was found to be in the pre-auricular approach (5\%). Unfavorable scaring was recorded the most for submandibular and transparotid approaches in comparison to the preauricular group. Owing to the fact that the pre auricular incision lies in the pre auricular fold making it inconspicuous. Wound infection was more in the submandibular group (20\%) when compared to $10 \%$ and $5 \%$ in the pre auricular and transparotid group respectively. It could be attributed to the fact that submandibular approach requires, long incision, more exposure, deep tunneling to reach the subcondylar area, due to its increased distance from the fracture line. Transient Malocclusion was seen in only in $10 \%$ of the case in the pre auricular group, which could be due to improper anatomic reduction and plate fixation of the fracture fragments, which is usually difficult using the preauricular approach. These cases were managed with post-op IMF for 3 weeks thereby setteling occlusion. Implant retrieval was done in 2 of the cases in pre auricular group and one case in 
the transparotid group due to the presence of continued infection.

Table 1

\begin{tabular}{|c|c|c|c|c|c|c|c|c|c|}
\hline & & \multicolumn{2}{|c|}{ Pre-auricular } & \multicolumn{2}{|c|}{ Sub-mandibular } & \multicolumn{2}{|c|}{ Transparotid } & \multirow{2}{*}{$\begin{array}{c}\text { Chi-square } \\
\text { value }\end{array}$} & \multirow[t]{2}{*}{$P$ value } \\
\hline & & Frequency & Percent & Frequency & Percent & Frequency & Percent & & \\
\hline \multirow[t]{2}{*}{ Post op infection } & No & 18 & 90.0 & 20 & 100.0 & 20 & 100.0 & \multirow[t]{2}{*}{4.13} & \multirow[t]{2}{*}{0.12} \\
\hline & Yes & 2 & 10.0 & 0 & 0 & 0 & 0 & & \\
\hline \multirow{2}{*}{$\begin{array}{l}\text { Palsy of facial } \\
\text { nerve }\end{array}$} & No & 19 & 95.0 & 16 & 80.0 & 17 & 85.0 & \multirow[t]{2}{*}{2.01} & \multirow[t]{2}{*}{0.36} \\
\hline & Yes & 1 & 5.0 & 4 & 20.0 & 3 & 15.0 & & \\
\hline \multirow[t]{2}{*}{ Scar } & No & 18 & 90.0 & 14 & 70.0 & 14 & 70.0 & \multirow[t]{2}{*}{2.98} & \multirow[t]{2}{*}{0.22} \\
\hline & Yes & 2 & 10.0 & 6 & 30.0 & 6 & 30.0 & & \\
\hline \multirow[t]{2}{*}{ Wound infection } & No & 18 & 90.0 & 16 & 80.0 & 19 & 95.0 & \multirow[t]{2}{*}{4.13} & \multirow[t]{2}{*}{0.12} \\
\hline & Yes & 2 & 10.0 & 4 & 20.0 & 1 & 5.0 & & \\
\hline \multirow{3}{*}{ Malocclusion } & & & & & & & & \multirow{3}{*}{4.13} & \multirow{3}{*}{0.12} \\
\hline & No & 18 & 90.0 & 20 & 100.0 & 20 & 100.0 & & \\
\hline & Yes & 2 & 10.0 & 0 & 0 & 0 & 0 & & \\
\hline \multirow[t]{2}{*}{ Plate retrieval } & No & 18 & 90.0 & 20 & 100.0 & 19 & 95.0 & \multirow[t]{2}{*}{2.10} & \multirow[t]{2}{*}{0.67} \\
\hline & Yes & 2 & 10.0 & 0 & 0 & 1 & 5.0 & & \\
\hline
\end{tabular}

\section{Conclusion}

Open reduction and internal fixation of condylar fractures have proven to provide better results. The preferred surgical approach should be the one that allows straightforward fracture management whilst minimizing the potential risks. Within the limitations of this retrospective study, we would like to conclude that inferior neck fractures seem to benefit from ORIF via submandibular approach, high neck fractures via the transparotid fractures and the condylar head fractures via the pre auricular approach with a low rate of complications.

\section{Conflict of Interest: None.}

\section{References}

1. Miloro M, Ghali GE, Larsen P, Peterson LJ, Waite P. Peterson's principles of oral and maxillofacial surgery. PMPHUSA; 2004.

2. Villarreal PM, Monje F, Junquera LM, Mateo J, Morillo AJ, Gonzalez C. Mandibular condyle fractures: determinants of treatment and outcome. J Oral Maxillofac Surg 2004;62(2):155e-63.

3. Nussbaum ML, Laskin DM, Best AM. Closed versus open reduction of mandibularcondylar fractures in adults: a metaanalysis. J Oral Maxillofac Surg 2008;66(6):1087e1092

4. MacLennan WD: Fractures of the mandibular condylar process. Br J Oral Surg 1969;7(1):31e39.

5. Lindahl L. Condylar fractures of the mandible. I. Classification and relation to age, occlusion, and concomitant injuries of teeth and teeth-supporting structures, and fractures of the mandibular body. Int J Oral Surg 1977;6(1):12e21.

6. Newman L. A clinical evaluation of the long-term outcome of patientstreated for bilateral fracture of the mandibular condyles. Br J Oral Maxillofac Surg 1998;36:176-9.

7. Imai T, Fujita Y, Motoki A, Takaoka H, Kanesaki T, Ota Y, Iwai S, Chisoku H, Ohmae M, Sumi T, Nakazawa M. Surgical approaches for condylar fractures related to facial nerve injury: deep versus superficial dissection. Int J Oral Maxillofac Surg 2019 Mar 2.
8. Zachariades N, Mezitis M, Mourouzis C, Papadakis D, Spanou A. Fractures of the mandibular condyle: a review of 466 cases. Literature review, reflections on treatment and proposals. $J$ Cranio-Maxillofac Surg 2006;;34(7):421-32.

9. Handschel J, Rüggeberg T, Depprich R, Schwarz F, Meyer U, Kübler NR, Naujoks C. Comparison of various approaches for the treatment of fractures of the mandibular condylar process. $J$ Cranio-Maxillofac Surg 2012;40(8):e397-401.

10. De Riu G, Gamba U, Anghinoni M, Sesenna E. A comparison of open and closed treatment of condylar fractures: a change in philosophy. Int J Oral Maxillofac Surg 2001;30(5):384-9.

11. Ebenezer V, Ramalingam B. Comparison of approaches for the rigid fixation of sub-condylar fractures. J Maxillofac Oral Surg 2011;10(1):38-44.

12. Loukota RA, Eckelt U, De Bont L, Rasse M. Subclassification of fractures of the condylar process of the mandible. $\mathrm{Br} \mathrm{J} \mathrm{Oral}$ Maxillofac Surg 2005;43(1):72-3.

13. Newman L. A clinical evaluation of the long-term outcome of patientstreated for bilateral fracture of the mandibular condyles. Br J Oral Maxillofac Surg 1998;36:176-9.

14. Wong KH. Mandible fractures: A 3-year retrospective study of cases seenin an oral surgical unit in Singapore. Singapore Dent $J$ 2000;23:6-10.

15. Badar MA, Syed SA. Etiology of mandibular condylar fractures; a study from tertiary care hospital of Lahore. PODJ 2014;34:42-5.

16. Sawazaki R, Lima Júnior SM, Asprino L, Moreira RW, de Moraes M. Incidence and patterns of mandibular condyle fractures. J Oral Maxillofac Surg 2010;68:1252-9.

17. Kellman RM. Maxillofacial trauma. In: Cummings Otolaryngology Head and Neck Surgery. 5th ed. Philadelphia: Mosby; 2010. p. 318-41.

18. Ellis E 3rd. Method to determine when open treatment of condylar processfractures is not necessary. J Oral Maxillofac Surg 2009;67:1685-90.

How to cite this article: Patel AKN, Girish G, Sneha TR. Comparison of three surgical approaches for fractures of themandibular condyle. J Oral Med, Oral Surg, Oral Pathol, Oral Radiol 2019;5(2):30-2. 